\title{
Testicular Sarcoma
}

National Cancer Institute

\section{Source}

National Cancer Institute. Testicular Sarcoma. NCI Thesaurus. Code C6359.

A sarcoma that arises from the testis. The majority of cases arise from teratomas or spermatocytic seminomas. 